\title{
Outcomes of health-related quality of life after open, laparoscopic, or robot-assisted radical prostatectomy in China
}

This article was published in the following Dove Medical Press journal: Cancer Management and Research

\author{
Wei Huang \\ Yan Zhang \\ Bai-Hua Shen \\ Shuo Wang \\ Hong-Zhou Meng \\ Xiao-Dong Jin
}

Department of Urology, The First Affiliated Hospital, Zhejiang University School of Medicine, Hangzhou, Zhejiang, China
Correspondence: Xiao-Dong Jin Department of Urology, The First Affiliated Hospital, Zhejiang University School of Medicine, Qingchun Road 79, Hangzhou 310003, Zhejiang, China

Tel +8613757191398

Fax +86 57I 87236832

Email xiaodong-jin@zju.edu.cn
Purpose: To compare the outcomes of health-related quality of life (HRQOL) in patients undergoing open (ORP), laparoscopic (LRP), or robot-assisted (RARP) radical prostatectomy. Patients and methods: We retrospectively analyzed 347 men with clinically localized prostate cancer treated with ORP ( $n=97)$, LRP $(n=71)$, or RARP $(n=179)$ by high-volume surgeons in our institution between January 2014 and December 2016. The primary endpoint was HRQOL including urinary incontinence and erectile dysfunction.

Results: One year after surgery, $15.9 \%$ of men reported moderate to severe urinary incontinence (ORP $16.5 \%$, LRP $15.4 \%$, and RARP $15.7 \%$ ), with only $4.6 \%$ using pads. There were no statistically significant differences in the ratios of no pad usage and urinary incontinence bother after 12 months postoperatively among the three groups. However, $67.7 \%$ of the men reported moderate to severe erectile dysfunction (ORP 66\%, LRP 66.1\%, and RARP 69.3\%) 12 months after surgery. There was no statistically significant difference in the international index of erectile function-5 (IIEF-5) postoperatively among the different surgical groups. In the univariate and multivariate analyses, age at surgery, preoperative IIEF-5, and neurovascular bundle preservation were the risk factors for moderate to severe sexual bother. Interestingly, $16.1 \%$ of men with an erection hardness score of grade 3-4 were hesitant to become sexually active postoperatively. Conclusion: ORP, LRP, and RARP have similar early HRQOL outcomes with respect to urinary incontinence and erectile dysfunction. In contrast to urinary continence, erectile dysfunction is still a serious concern for patients who undergo radical prostatectomy.

Keywords: erectile dysfunction, prostate cancer, radical prostatectomy, urinary incontinence

\section{Introduction}

Radical prostatectomy (RP) has been the standard first-line choice for the treatment of patients with clinically localized prostate cancer. ${ }^{1}$ Open RP (ORP), as the traditional surgical approach, has been used and established for a long time. ${ }^{2}$ Minimally invasive techniques, such as robot-assisted RP (RARP) and laparoscopic RP (LRP), have been developed as two additional alternative intervention approaches and have frequently been performed in prostate cancer patients in recent years. ${ }^{3}$ Laparoscopic methods have been developed over 20 years; however, reviews of surgical outcomes do not favor laparoscopy over ORP., ${ }^{4,5}$ RARP was first performed by Binder and Kramer ${ }^{6}$ and Abbou et $\mathrm{al}^{7}$ in 2001 and became widely utilized thereafter. Currently, RARP has been accepted as one of the most favored choices in the treatment of prostate cancer because of its advantages in achieving better surgical outcomes than the other two RP techniques. ${ }^{8,9}$ However, some studies showed that RARP does not result in favorable 
sexual function outcomes after surgery, compared with ORP or LRP. ${ }^{10,11}$ The choice of surgical technique for prostate cancer is controversial because no consistent differences have been demonstrated. Moreover, few studies have compared the three surgical techniques at the same medical center.

In this study, we retrospectively collected the perioperative clinical data of patients with localized prostate cancer who underwent ORP, LRP, or RARP from January 2014 to December 2016 in our center. Our study aimed to evaluate the outcomes health-related quality of life (HRQOL) following ORP, LRP, and RARP, as well as to determine whether different surgical techniques affect HRQOL outcomes in patients with clinically localized prostate cancer.

\section{Patients and methods}

\section{Patient selection}

From January 2014 to December 2016, patients aged $<70$ years with clinically localized prostate cancer (cT1-T2), who underwent ORP, LRP, or RARP in our center, were identified through a computer search in the disease database of our hospital. The inclusion criteria were the following: 1) diagnosed with clinically localized prostate cancer; 2) postoperative follow-up time $>12$ months; 3 ) no preoperatively severe erectile dysfunction (international index of erectile function-5 [IIEF-5] $\geq 8$ ); 4) no prior treatment for prostate cancer, such as radiotherapy and endocrine therapy; 5) no previous history of major pelvic surgery; and 6) no other concurrent cancer (Figure 1). All

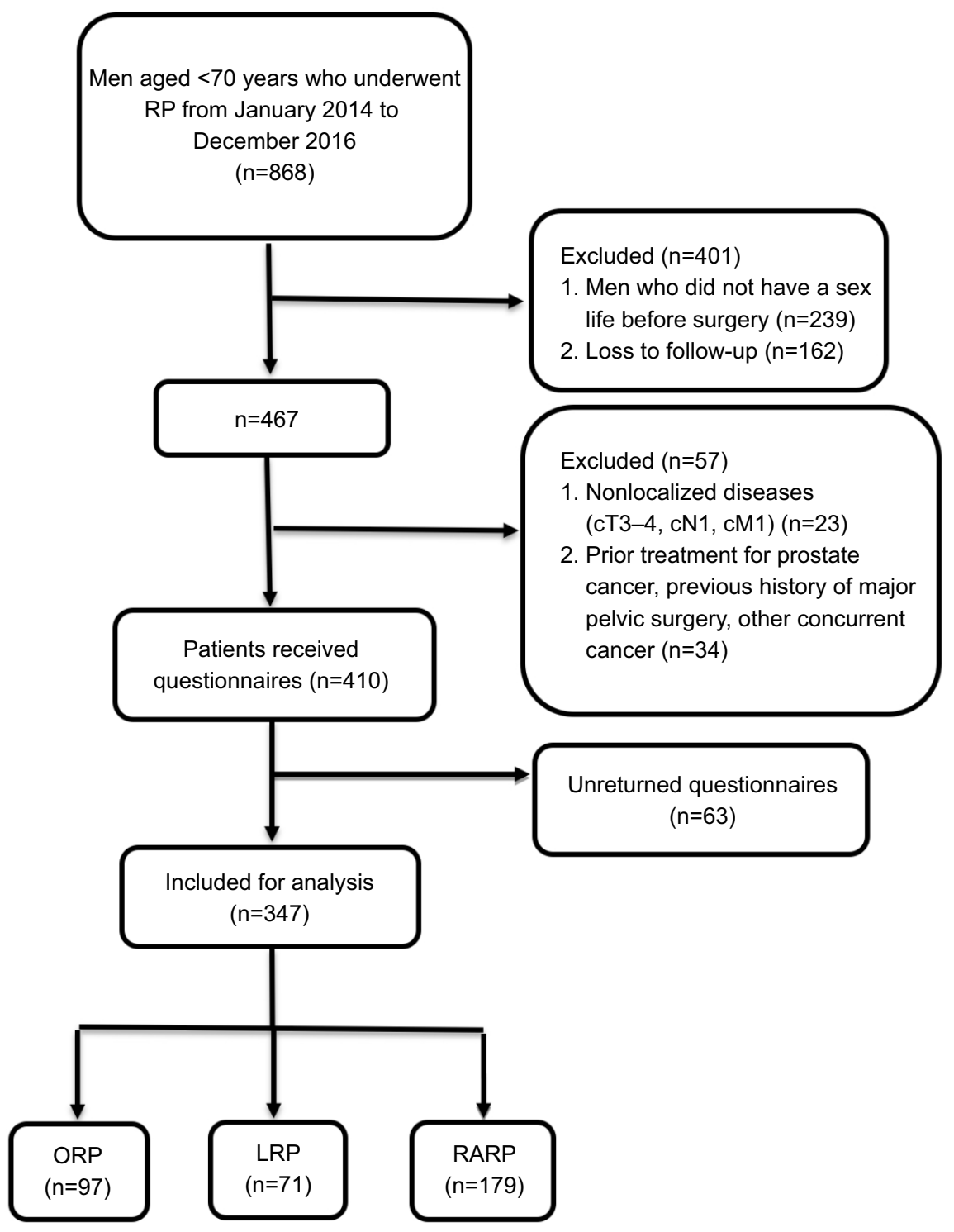

Figure I Patient flowchart.

Abbreviations: LRP, laparoscopic radical prostatectomy; ORP, open radical prostatectomy; RARP, robot-assisted radical prostatectomy. 
procedures in our study were performed by high-volume surgeons defined by an average per-surgeon case volume of $\geq 25$ cases per year. ${ }^{12}$

\section{Data collection}

The following data were recorded: patient age at surgery, surgical technique, body mass index, international prostate symptom score (IPSS), preoperative IIEF-5, prostate volume, preoperative level of prostate-specific antigen, clinical T-stage, biopsy Gleason score, D'Amico risk classification, ${ }^{13}$ operative time, perioperative bleeding, pathological Gleason score, pathological TNM stage, neurovascular bundle preservation status, surgical margin status, and postoperative treatments such as androgen deprivation therapy (ADT) or radiation therapy (RT).

\section{Evaluation of HRQOL outcomes}

All patients were assessed postoperatively for HRQOL, including urinary incontinence and erectile dysfunction, for at least 12 months. All patients were contacted through telephone interviews, and the men who met the abovementioned inclusion criteria received a questionnaire via email and phone. Postoperative urinary incontinence and erectile dysfunction were assessed by telephone or mailed questionnaires.

The primary endpoint was urinary incontinence and erectile dysfunction 12 months after surgery. Urinary incontinence and erectile dysfunction were assessed using the "bother" items adapted from the Expanded Prostate Cancer Index Composite questionnaires. ${ }^{14}$ Patients reported the severity of bother for each domain. Possible responses included no bother, very small bother, small bother, moderate bother, and severe bother. Responses were dichotomized with the response of moderate/severe bother as the outcome of interest for the statistical analyses. For the self-reported assessment of urinary incontinence, we asked, "When do you use no pad, a diaper, or other sanitary protection postoperatively during a typical 24 hours?" The response options were "none", "no pad usage after 1 week", "no pad usage after 1 month", "no pad usage after 3 months", "no pad usage after 6 months", and "no pad usage after 1 year". For the selfreported assessment of erectile dysfunction, the IIEF-5 score was used preoperatively and postoperatively. The assessment of erectile dysfunction also included the following question: "Do you have spontaneous morning erection(s) after surgery, and how would you rate your erection hardness score (EHS) when you have an erection after surgery?"15 The EHS was scored as follows: $0=$ no erection; $1=$ flaccid but sense of fullness; 2 = partial erection but not sufficient for penetration; $3=$ firm enough for penetration but still not satisfactory; and $4=$ firm enough for penetration with satisfaction.

\section{Statistical analyses}

A univariate comparison of the covariates among ORP, LRP, and RARP patients was performed using Student's $t$-test or the Mann-Whitney $U$ test, and Pearson's chi-squared test, Mantel-Haenszel chi-squared test or Fisher's exact test was used for categorical variables. Univariate and multivariate logistic regression analyses were used to assess the associations of clinicopathologic characteristics with the response of moderate/severe bother regarding erectile dysfunction postoperatively. Statistical analyses were performed using SPSS version 21 (IBM Corporation, Armonk, NY, USA), and a two-tailed $P$-value $<0.05$ was considered statistically significant.

\section{Ethics statement}

The retrospective study protocol was reviewed and approved by the institutional review board of the First Affiliated Hospital, Zhejiang University School of Medicine. Informed consent was obtained from all enrolled subjects. The patient consent was written informed consent, and this study was conducted in accordance with the Declaration of Helsinki.

\section{Results \\ Patient characteristics}

A total of 347 eligible men were included in this study, of whom 97, 71, and 179 underwent ORP, LRP, and RARP, respectively. Clinical data are presented in Table 1 and are stratified by the surgical technique. The mean age at surgery in the ORP, LRP, and RARP groups was 63.6 $55.2,64.2 \pm 4.1$, and 63.5 \pm 5.6 years, respectively $(P=0.57)$.

Pre- and postoperative tumor characteristics did not differ significantly, except that the clinical and pathological T-stages were significantly different among the ORP, LRP, and RARP groups. The proportion of clinical stages $\mathrm{T} 1 \mathrm{a} / \mathrm{b}, \mathrm{T} 1 \mathrm{c}$, and $\mathrm{T} 2$ among the ORP $(0 \%, 11.3 \%$, and $88.7 \%$, respectively), LRP $(2.9 \%, 30.9 \%$, and $66.2 \%$, respectively), and RARP ( $0 \%$, $7.8 \%$, and $92.2 \%$, respectively) groups was significantly different $(P<0.001)$. The proportion of pathological stages $\mathrm{T} 2$ or lower, T3a, T3b, and T4 among the ORP $(57.7 \%, 27.8 \%$, $11.4 \%$, and $3.1 \%$, respectively), LRP $(56.3 \%, 33.8 \%, 8.5 \%$, and $1.4 \%$, respectively), and RARP $(73.2 \%, 20.7 \%, 5.6 \%$, and $0.5 \%$, respectively) groups was also significantly different $(P<0.047)$. There was no significant difference among the three groups regarding neurovascular bundle preservation 
Table I Patient characteristics stratified by the surgical technique

\begin{tabular}{|c|c|c|c|c|}
\hline Variables & ORP $(n=97)$ & $\operatorname{LRP}(n=7 I)$ & $\operatorname{RARP}(n=179)$ & $P$-value \\
\hline Age at surgery, years, mean \pm SD & $63.6 \pm 5.2$ & $64.2 \pm 4.1$ & $63.5 \pm 5.6$ & 0.57 \\
\hline Preoperative BMI, $\mathrm{kg} / \mathrm{m}^{2}$, mean \pm SD & $24.1 \pm 2.6$ & $23.7 \pm 2.6$ & $23.5 \pm 2.7$ & 0.29 \\
\hline IPSS score, mean \pm SD & $8.9 \pm 9.3$ & $9.0 \pm 9.1$ & $7.3 \pm 7.4$ & 0.31 \\
\hline Preoperative IIEF-5 score, mean \pm SD & $18.1 \pm 5.7$ & $19.1 \pm 4.9$ & $19.4 \pm 4.1$ & 0.39 \\
\hline Prostate volume, $\mathrm{mL}$, mean $\pm \mathrm{SD}$ & $31.3 \pm 12.8$ & $34.5 \pm 19.2$ & $31.8 \pm 16.1$ & 0.45 \\
\hline Preoperative PSA level, $\mathrm{ng} / \mathrm{mL}$, mean \pm SD & $16.7 \pm 15.5$ & $17.9 \pm 17.0$ & $22.3 \pm 40.2$ & 0.29 \\
\hline \multicolumn{5}{|l|}{ Biopsy Gleason score } \\
\hline$\leq 6$ & $35(36.1)$ & $21(29.5)$ & $46(25.6)$ & 0.43 \\
\hline 7 & $44(45.4)$ & $32(45.1)$ & $90(50.3)$ & \\
\hline$\geq 8$ & $18(18.5)$ & $18(25.4)$ & $43(24.1)$ & \\
\hline \multicolumn{5}{|l|}{ Clinical stage } \\
\hline $\mathrm{cTIa} / \mathrm{b}$ & $0(0)$ & $2(2.9)$ & $0(0)$ & $<0.001$ \\
\hline cTIc & II (II.3) & $22(30.9)$ & $14(7.8)$ & \\
\hline cT2 & $86(88.7)$ & $47(66.2)$ & $165(92.2)$ & \\
\hline \multicolumn{5}{|l|}{ D'Amico risk classification } \\
\hline Low risk & $\mathrm{II}(\mathrm{II} .3)$ & I5 (2I.I) & $37(20.7)$ & 0.31 \\
\hline Intermediate risk & $40(4 \mid .2)$ & $25(35.2)$ & $59(33.0)$ & \\
\hline High risk & $46(47.4)$ & $31(43.7)$ & $83(46.4)$ & \\
\hline Operation time, minutes, mean \pm SD & $166.7 \pm 39.0$ & $187.9 \pm 67.9$ & $181.6 \pm 58.1$ & 0.04 \\
\hline Perioperative bleeding, $\mathrm{mL}$, mean $\pm \mathrm{SD}$ & $273.3 \pm 157.9$ & $122.7 \pm 169.4$ & $76.4 \pm 78.5$ & 0.001 \\
\hline \multicolumn{5}{|l|}{ Pathological Gleason score } \\
\hline$\leq 6$ & $20(20.6)$ & $18(25.4)$ & $46(25.7)$ & 0.91 \\
\hline 7 & $48(49.5)$ & $33(46.5)$ & $85(47.5)$ & \\
\hline$\geq 8$ & $29(29.9)$ & $20(28.1)$ & $48(26.8)$ & \\
\hline \multicolumn{5}{|l|}{ Pathological T-stage } \\
\hline pT2 or lower & $56(57.7)$ & $40(56.3)$ & $|3|(73.2)$ & 0.047 \\
\hline pT3a & $27(27.8)$ & $24(33.8)$ & $37(20.7)$ & \\
\hline pT3b & II (II.4) & $6(8.5)$ & $10(5.6)$ & \\
\hline pT4 & $3(3.1)$ & $\mathrm{I}(\mathrm{I} .4)$ & $\mathrm{I}(0.5)$ & \\
\hline \multicolumn{5}{|l|}{ Pathological N-stage } \\
\hline $\mathrm{pNx}$ & $2(2)$ & $6(8.5)$ & $5(2.8)$ & 0.12 \\
\hline pNo & $89(91.8)$ & $62(87.3)$ & $167(93.3)$ & \\
\hline $\mathrm{pNI}$ & $6(6.2)$ & $3(4.2)$ & $7(3.9)$ & \\
\hline \multicolumn{5}{|l|}{ Neurovascular bundle preservation } \\
\hline None & $73(75.3)$ & $50(70.4)$ & $122(68.2)$ & 0.74 \\
\hline Unilateral & $11(11.3)$ & $10(14.1)$ & $23(12.8)$ & \\
\hline Bilateral & $13(13.4)$ & II (I5.5) & $34(19)$ & \\
\hline Positive surgical margin (\%) & $25(25.8)$ & $23(32.4)$ & $54(30.2)$ & 0.62 \\
\hline Positive neurovascular bundle (\%) & $25(25.7)$ & $25(35.2)$ & $62(34.6)$ & 0.27 \\
\hline Postoperative ADT & $7(7.2 \%)$ & $5(7.0 \%)$ & $9(5.0 \%)$ & 0.71 \\
\hline Postoperative RT & $7(7.2 \%)$ & $6(8.5 \%)$ & II (6.1\%) & 0.80 \\
\hline
\end{tabular}

Abbreviations: ADT, androgen deprivation therapy; BMI, body mass index; IIEF-5, international index of erectile function-5; IPSS, international prostate symptom score; LRP, laparoscopic radical prostatectomy; ORP, open radical prostatectomy; PSA, prostate-specific antigen; RARP, robot-assisted radical prostatectomy; RT, radiation therapy.

and frequencies of postoperative treatment with ADT or RT. All the patients had not used any phosphodiesterase type 5-inhibitor, vacuum therapy, or other erectile aids during these 12 months.

\section{Urinary incontinence}

There was no significant difference among the groups regarding preoperative IPSS scores $(P=0.31)$. The proportion of immediately pad-free patients after the removal of the postoperative catheter in the ORP, LRP, and RARP groups was $24.7 \%, 14.1 \%$, and $24 \%$, respectively $(P=0.12)$. The proportion of pad-free patients 1 year postoperatively in the ORP, LRP, and RARP groups was 96.9\%, 93.0\%, and 95.5\%, respectively $(P=0.48)$. In general, there were no statistically significant differences in the proportion of pad-free patients among the ORP, LRP, and RARP groups during the 12-month 
follow-up after RP (Table 2). The proportion of pad-free patients over time is presented in Figure 2. Responses to the urinary incontinence questions are summarized in Table 3. Overall, $15.9 \%$ of the patients reported moderate/severe urinary bother at 12 months. No significant difference was observed in the proportion of self-reported urinary bother among surgical techniques at the 12-month follow-up after $\operatorname{RP}(P=0.13)$.

\section{Erectile dysfunction}

Responses to sexual function domain questions are summarized in Table 3. Patients who had severe erectile dysfunction preoperatively, patients who missed the follow-up, or patients who had undergone prior treatment for prostate cancer, such as ADT and RT, were excluded. There was no significant difference among the groups regarding the preoperative IIEF-5 score $(P=0.39)$. Importantly, there was also no significant difference among the groups regarding the postoperative IIEF-5 score $(P=0.18)$ at the 12-month follow-up. Overall, 67.7\% of the patients reported a moderate/severe sexual bother,
$21.6 \%$ reported a moderate bother, and $44.4 \%$ reported a severe bother in the ORP group; $25.4 \%$ and $40.7 \%$ reported a moderate and severe bother, respectively, in the LRP group; and $20.7 \%$ and $48.6 \%$ reported a moderate and severe bother, respectively, in the RARP group $(P=0.22)$. Additionally, $76.3 \%, 73.2 \%$, and $70.4 \%$ of the patients reported no spontaneous morning erection in the ORP, LRP, and RARP groups, respectively ( $P=0.57$ ). Additionally, 29.9\%, 32.4\%, and $36.3 \%$ of the patients reported having sufficient penis hardness for intercourse in the ORP, LRP, and RARP groups, respectively $(P=0.54)$. Interestingly, $16.1 \%$ of the men with EHS grade 3-4 were hesitant to become sexually active postoperatively.

In the univariate logistic regression analysis, the factors that were positively associated with reports of a moderate/ severe sexual bother were age at surgery, preoperative IIEF-5 score, and neurovascular bundle preservation (Table 4). In the multivariate logistic regression analysis, the factors that were independently associated with reports of a moderate/ severe sexual bother at the 12-month follow-up were an older

Table 2 Postoperative urinary incontinence outcome stratified by surgical technique

\begin{tabular}{|l|l|l|l|l|}
\hline Pads for incontinence & ORP (n=97) & LRP (n=7I) & RARP (n=I79) & P-value \\
\hline None & $24(24.7)$ & $10(14.1)$ & $43(24.0)$ & 0.12 \\
\hline No pad usage after I week & $29(29.9)$ & $16(22.5)$ & $62(34.6)$ & 0.17 \\
\hline No pad usage after I month & $44(45.4)$ & $37(52.1)$ & $107(60.0)$ & 0.07 \\
\hline No pad usage after 3 months & $74(76.3)$ & $53(74.6)$ & $140(78.2)$ & 0.82 \\
\hline No pad usage after 6 months & $89(9 I .8)$ & $62(87.3)$ & $163(9 I .1)$ & 0.58 \\
\hline No pad usage after I year & $94(96.9)$ & $66(93.0)$ & I7I (95.5) & 0.48 \\
\hline
\end{tabular}

Abbreviations: LRP, laparoscopic radical prostatectomy; ORP, open radical prostatectomy; RARP, robot-assisted radical prostatectomy.

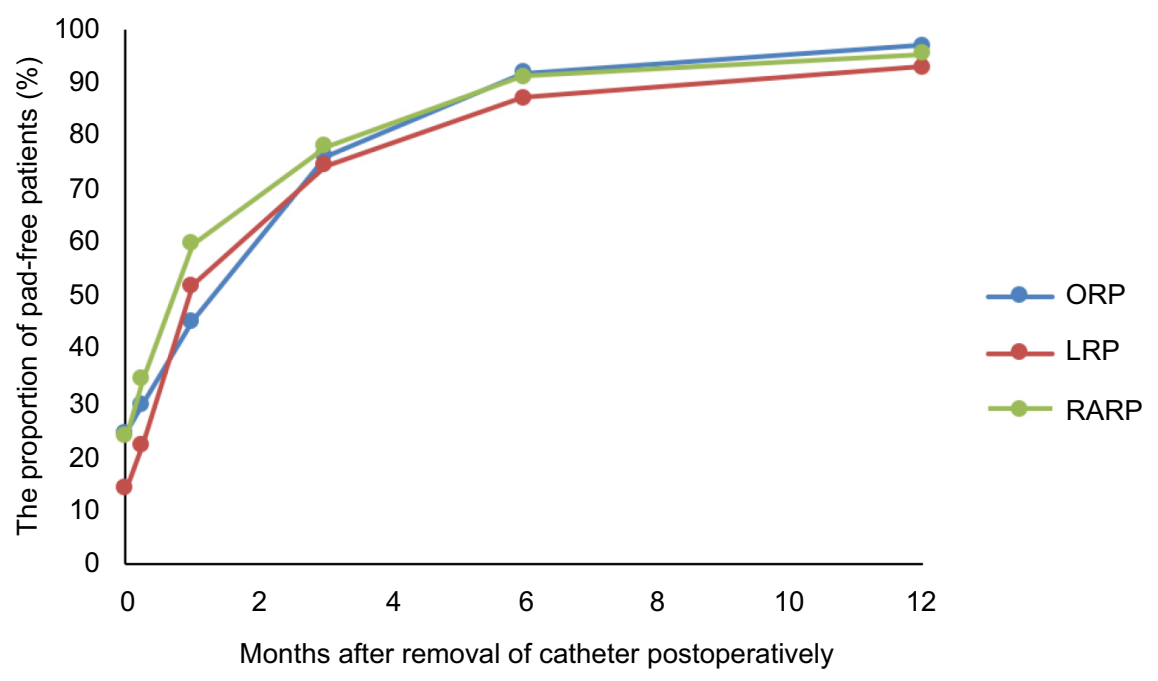

Figure 2 The proportion of pad-free patients.

Abbreviations: LRP, laparoscopic radical prostatectomy; ORP, open radical prostatectomy; RARP, robot-assisted radical prostatectomy. 
Table 3 Postoperative urinary and sexual outcomes stratified by the surgical technique

\begin{tabular}{|c|c|c|c|c|}
\hline Parameter & ORP $(n=97)$ & $\operatorname{LRP}(n=7 I)$ & RARP $(n=179)$ & P-value \\
\hline \multicolumn{5}{|l|}{ Urinary domain, $\mathrm{n}(\%)$} \\
\hline \multicolumn{5}{|l|}{ I2-month urinary bother, n (\%) } \\
\hline No bother & $25(25.8)$ & $19(26.8)$ & $47(26.3)$ & 0.13 \\
\hline Very small bother & $20(20.6)$ & $8(1 \mathrm{I} .3)$ & $45(25.1)$ & \\
\hline Small bother & $36(37.1)$ & $33(46.5)$ & $59(32.9)$ & \\
\hline Moderate bother & $10(10.3)$ & $7(9.8)$ & $25(14.0)$ & \\
\hline Severe bother & $6(6.2)$ & $4(5.6)$ & $3(1.7)$ & \\
\hline \multicolumn{5}{|l|}{ Sexual domain, $\mathrm{n}(\%)$} \\
\hline \multicolumn{5}{|l|}{ I2-month sexual bother, n (\%) } \\
\hline No bother & $19(19.6)$ & $12(16.9)$ & $15(8.4)$ & 0.22 \\
\hline Very small bother & $6(6.2)$ & $6(8.5)$ & $16(8.9)$ & \\
\hline Small bother & $8(8.2)$ & $6(8.5)$ & $24(13.4)$ & \\
\hline Moderate bother & $21(21.6)$ & $18(25.4)$ & $37(20.7)$ & \\
\hline Severe bother & $43(44.4)$ & $29(40.7)$ & $87(48.6)$ & \\
\hline IIEF-5 score, mean \pm SD & $5.3 \pm 4.9$ & $6.2 \pm 5.3$ & $7.1 \pm 5.6$ & 0.18 \\
\hline No spontaneous morning erection, $\mathrm{n}(\%)$ & $74(76.3)$ & $52(73.2)$ & $126(70.4)$ & 0.57 \\
\hline Penile firm enough for intercourse, $n$ (\%) & $29(29.9)$ & $23(32.4)$ & $65(36.3)$ & 0.54 \\
\hline
\end{tabular}

Abbreviations: IIEF-5, international index of erectile function-5; LRP, laparoscopic radical prostatectomy; ORP, open radical prostatectomy; RARP, robot-assisted radical prostatectomy.

age at surgery $(\mathrm{OR}=1.11,95 \% \mathrm{CI}=1.01-1.23, P=0.039)$ and a higher preoperative IIEF-5 score (OR $=1.31,95 \% \mathrm{CI}$ $=1.20-1.42, P<0.001)$, as shown in Table 5. Bilateral neurovascular bundle preservation $(\mathrm{OR}=0.10,95 \% \mathrm{CI}=0.03-0.37$, $P<0.001)$ was also an independent predictor of a moderate/ severe sexual bother, decreasing the odds of bother when compared with none or unilateral neurovascular bundle preservation. Thus, surgical techniques were not associated with sexual dysfunction outcomes in both the univariate and multivariate analyses.

\section{Positive surgical margin}

Positive surgical margins were observed in $25.8 \%, 32.4 \%$, and $30.2 \%$ of the patients in the ORP, LRP, and RARP groups, respectively $(P=0.62)$. The frequencies of a positive surgical margin were not associated with sexual dysfunction outcomes (OR $=1.02,95 \% \mathrm{CI}=0.21-4.84, P=0.983)$.

\section{Discussion}

$\mathrm{RP}$ is widely performed in patients with clinically localized prostate cancer. With the widespread application of RARP in recent years, increasingly more concerns regarding urinary incontinence and erectile dysfunction after RP have arisen. ${ }^{16}$ As RARP is being performed successfully at high-volume centers, many reports have demonstrated improved results in urinary incontinence and erectile dysfunction recovery. A large prospective, controlled, nonrandomized trial showed that there was no significant difference in urinary incontinence 12 months after surgery between the RARP and ORP groups. Furthermore, erectile function was preserved 12 months after RARP. ${ }^{17}$ However, a recent study of high-volume surgeons showed that urinary incontinence and erectile dysfunction outcomes did not differ according to the surgical technique (ORP, LRP, and RARP). ${ }^{12}$

In this study, our analyses of urinary incontinence and erectile dysfunction were based on patients' self-reported experiences of urinary incontinence and erectile dysfunction using a validated questionnaire. All procedures in our study were performed by high-volume surgeons. Importantly, there was no statistically significant difference in urinary incontinence or erectile dysfunction among the ORP, LRP, and RARP groups. With the questionnaire, we found that $22.2 \%$ of men used no pads after the removal of the postoperative catheter and $95.4 \%$ of men used no pads 1 year postoperatively. Only $15.9 \%$ of men reported a moderate/severe urinary bother at the 12-month follow-up after RP.

In contrast to urinary incontinence, the outcome of erectile dysfunction was less favorable. The postoperative IIEF-5 score was significantly lower than the preoperative score, with $67.7 \%$ of men reporting a moderate/severe sexual bother after RP and only $33.7 \%$ of men reporting sufficient penis hardness for intercourse. Additionally, many studies have assessed patients' self-reported outcomes of urinary and sexual function after RP. A recent study evaluated the functional outcomes of 206 patients who underwent ORP and LRP at a 12-month follow-up. ${ }^{18}$ This study showed that there was 
Table 4 Univariate analysis of clinicopathologic features associated with a moderate or big sexual bother over the preceding 4 weeks

\begin{tabular}{|c|c|c|c|}
\hline Variables & OR & $95 \% \mathrm{Cl}$ & $P$-value \\
\hline \multicolumn{4}{|l|}{ Surgical technique } \\
\hline ORP & Reference & Reference & \\
\hline LRP & 2.42 & $0.63-9.33$ & 0.200 \\
\hline RARP & 1.13 & $0.43-2.96$ & 0.805 \\
\hline Age at surgery (years) & 1.13 & $1.00-1.27$ & 0.045 \\
\hline BMI & 0.98 & $0.85-1.45$ & 0.883 \\
\hline IPSS score & 0.96 & $0.89-1.04$ & 0.368 \\
\hline Preoperative IIEF-5 score & 1.32 & I.19-1.47 & $<0.001$ \\
\hline Prostate volume & 1.01 & $0.99-1.03$ & 0.335 \\
\hline Preoperative PSA level & 1.01 & $0.99-1.03$ & 0.277 \\
\hline \multicolumn{4}{|l|}{ Biopsy Gleason score } \\
\hline$\leq 6$ & Reference & Reference & \\
\hline 7 & 0.98 & $0.25-3.85$ & 0.974 \\
\hline$\geq 8$ & 1.02 & $0.19-5.26$ & 0.978 \\
\hline \multicolumn{4}{|l|}{ Clinical stage } \\
\hline $\mathrm{cTla} / \mathrm{b}$ & Reference & Reference & \\
\hline cTIc & 0.17 & $0.01-14.21$ & 0.430 \\
\hline cT2 & 0.56 & $0.01-47.81$ & 0.796 \\
\hline \multicolumn{4}{|l|}{ D'Amico risk classification } \\
\hline Low risk & Reference & Reference & \\
\hline Intermediate risk & 2.00 & $0.46-8.67$ & 0.353 \\
\hline High risk & 2.03 & $0.19-21.66$ & 0.557 \\
\hline Operative time & 1.00 & $1.00-1.01$ & 0.293 \\
\hline Perioperative bleeding & 0.99 & $0.99-1.00$ & 0.698 \\
\hline \multicolumn{4}{|l|}{ Pathological Gleason score } \\
\hline$\leq 6$ & Reference & Reference & \\
\hline 7 & 0.69 & $0.17-2.78$ & 0.604 \\
\hline$\geq 8$ & 0.20 & $0.04-1.16$ & 0.073 \\
\hline \multicolumn{4}{|l|}{ Pathological T-stage } \\
\hline $\mathrm{pT} 2$ or lower & Reference & Reference & \\
\hline pT3a & 7.28 & $0.83-63.71$ & 0.073 \\
\hline $\mathrm{pT} 3 \mathrm{~b} / \mathrm{pT} 4$ & 3.11 & $0.19-51.45$ & 0.427 \\
\hline \multicolumn{4}{|l|}{$\begin{array}{l}\text { Neurovascular bundle } \\
\text { preservation }\end{array}$} \\
\hline None & Reference & Reference & \\
\hline Unilateral & 0.22 & $0.05-0.92$ & 0.038 \\
\hline Bilateral & 0.06 & $0.01-0.32$ & 0.001 \\
\hline Positive surgical margin & 1.02 & $0.21-4.84$ & 0.983 \\
\hline Positive neurovascular bundle & 0.65 & $0.04-11.65$ & 0.772 \\
\hline Postoperative ADT & 0.42 & $0.05-3.51$ & 0.426 \\
\hline Postoperative RT & 0.41 & $0.02-10.12$ & 0.583 \\
\hline Postoperative IIEF-5 score & 1.14 & $0.93-1.39$ & 0.203 \\
\hline
\end{tabular}

Abbreviations: $A D T$, androgen deprivation therapy; BMI, body mass index; IIEF5 , international index of erectile function-5; IPSS, international prostate symptom score; LRP, laparoscopic radical prostatectomy; ORP, open radical prostatectomy; PSA, prostate-specific antigen; RARP, robot-assisted radical prostatectomy; RT, radiation therapy.

no difference among surgical techniques. Additionally, $97 \%$ of men reported the use of less than one pad per day and $54 \%$ of men reported restoration of their formal sexual function. Barry et al reported a survey of 685 patients who underwent ORP and RARP at a median follow-up of 13.9 months. ${ }^{11}$ This
Table 5 Multivariate analysis of clinicopathologic features associated with a moderate or big sexual bother over the preceding 4 weeks

\begin{tabular}{|l|l|l|l|}
\hline Variables & OR & $\mathbf{9 5 \% ~ C I ~}$ & $\boldsymbol{P}$-value \\
\hline Age at surgery (years) & $\mathrm{I} . \mathrm{II}$ & $\mathrm{I} .0 \mathrm{I}-\mathrm{I} .23$ & 0.039 \\
\hline Preoperative IIEF-5 score & $\mathrm{I} .3 \mathrm{I}$ & $\mathrm{I} .20-\mathrm{I} .42$ & $<0.00 \mathrm{I}$ \\
\hline $\begin{array}{l}\text { Neurovascular bundle } \\
\text { preservation }\end{array}$ & & & \\
\hline None & Referent & Referent & \\
\hline Unilateral & 0.34 & $0.1 \mathrm{I}-\mathrm{I} .09$ & $0.07 \mathrm{I}$ \\
\hline Bilateral & 0.10 & $0.03-0.37$ & $<0.00 \mathrm{I}$ \\
\hline
\end{tabular}

Abbreviation: IIEF-5, international index of erectile function-5.

study showed that $88 \%$ and $31 \%$ of men reported significant sexual dysfunction or urinary incontinence after RP, respectively. Herlemann et al reported a longitudinal observational study of 1,892 patients who underwent ORP and RARP with a 3-year follow-up. ${ }^{19}$ This study showed that urinary and sexual quality of life outcomes were largely similar between the ORP and RARP groups. The differences in self-reported outcomes of urinary incontinence and sexual dysfunction in different studies may be explained by the definitions of urinary incontinence and erectile dysfunction as well as the volume-outcome relationship. Different studies have different definitions of the outcomes of urinary incontinence and erectile dysfunction. Furthermore, studies have observed superior oncological outcomes and improved urinary function outcomes for high-volume surgeons. ${ }^{20,21}$ Another possible reason is the postoperative follow-up time. Mandel et al reported that the probability of regaining continence in patients with urinary incontinence at 12 months post-RP was $38.6 \%$ after 24 months and $49.7 \%$ after 36 months. ${ }^{22}$ The corresponding rates among patients with erectile dysfunction at 12 months after RP were $30.8 \%$ at 24 months and $36.5 \%$ at 36 months.

In our study, we used a series of definitions to define sexual function after RP by asking several questions and found consistent results in the comparison of the three techniques. There was no significant difference regarding self-reported sexual bother, postoperative IIEF-5 score, spontaneous erection, and EHS among the ORP, LRP, and RARP groups. As erectile dysfunction outcomes are the result of multiple factors, we evaluated our patients to identify different factors between the patients who did and those who did not report moderate/severe sexual bother. None of the patients had severe erectile dysfunction preoperatively. The preoperative, perioperative, and postoperative factors were assessed to identify the associations of clinicopathologic characteristics with a response of moderate/ severe bother with respect to erectile dysfunction at 12 months 
post-RP. Although it has been reported that the minimum time for sexual function to be considered stabilized is $>18$ months, we evaluated this cohort at a 12-month follow-up. ${ }^{11}$ According to the literature, sexual function recovers relatively quickly during the first 12 months postoperatively and then slows or plateaus thereafter. ${ }^{23}$ Therefore, the factors associated with a response of moderate/severe sexual bother at 12 months post-RP are important, especially with respect to patients' expectations. In the multivariate logistic regression analysis, older age at surgery and a higher preoperative IIEF-5 score were independently associated with a response of moderate/ severe sexual bother. Bilateral neurovascular bundle preservation was also an independent predictor of a moderate/severe sexual bother, decreasing the odds of bother when compared with none or unilateral neurovascular bundle preservation. Other factors were not statistically significant between the patients who did and those who did not report a moderate/severe sexual bother. Interestingly, $16.1 \%$ of the men with EHS grade 3-4 were hesitant to become sexually active postoperatively; some of them even thought that sexual intercourse after surgery would harm their health, which likely reflected the difference in sexual attitude of Chinese people or indicated that the RP patients lacked sexual education from doctors.

\section{Limitations}

There are several limitations of this study. First, this study had a retrospective design and may have recollection bias. Second, the surgeons' experience varied and the administration of surveys was heterogeneous. Third, the sample size in our study was small and the follow-up time was not sufficient. A longer-term follow-up is needed.

\section{Conclusion}

ORP, LRP, and RARP have similar early HRQOL outcomes with respect to urinary incontinence and erectile dysfunction. In contrast to urinary continence, erectile dysfunction is still a serious concern for patients who undergo RP.

\section{Acknowledgment}

This study was funded by the National Natural Science Foundation of China (grant number 81370799) and the Natural Science Foundation of Zhejiang Province (grant number LGF18H050001).

\section{Author contributions}

Wei Huang and Yan Zhang are first authors. All authors contributed to data analysis, drafting and revising the article, gave final approval of the version to be published, and agree to be accountable for all aspects of the work.

\section{Disclosure}

The authors report no conflicts of interest in this work.

\section{References}

1. Evans SM, Millar JL, Davis ID, et al. Patterns of care for men diagnosed with prostate cancer in Victoria from 2008 to 2011. Med J Aust. 2013;198(10):540-545.

2. Resnick MJ, Koyama T, Fan KH, et al. Long-term functional outcomes after treatment for localized prostate cancer. $N$ Engl J Med. 2013;368(5):436-445.

3. Tyson MD, Andrews PE, Ferrigni RF, Humphreys MR, Parker AS, Castle EP. Radical prostatectomy trends in the United States: 1998 to 2011. Mayo Clin Proc. 2016;91(1):10-16.

4. Ficarra V, Novara G, Rosen RC, et al. Systematic review and metaanalysis of studies reporting urinary continence recovery after robotassisted radical prostatectomy. Eur Urol. 2012;62(3):405-417.

5. Moran PS, O'Neill M, Teljeur C, et al. Robot-assisted radical prostatectomy compared with open and laparoscopic approaches: a systematic review and meta-analysis. Int J Urol. 2013;20(3):312-321.

6. Binder J, Kramer W. Robotically-assisted laparoscopic radical prostatectomy. BJU Int. 2001;87(4):408-410.

7. Abbou CC, Hoznek A, Salomon L, et al. Remote laparoscopic radical prostatectomy carried out with a robot. Report of a case. Prog Urol. 2000;10(4):520-523.

8. Trinh QD, Sammon J, Sun M, et al. Perioperative outcomes of robotassisted radical prostatectomy compared with open radical prostatectomy: results from the nationwide inpatient sample. Eur Urol. 2012;61(4):679-685.

9. Menon M, Tewari A, Baize B, Guillonneau B, Vallancien G. Prospective comparison of radical retropubic prostatectomy and robot-assisted anatomic prostatectomy: the Vattikuti Urology Institute experience. Urology. 2002;60(5):864-868.

10. Litwin MS, Melmed GY, Nakazon T. Life after radical prostatectomy: a longitudinal study. J Urol. 2001;166(2):587-592.

11. Barry MJ, Gallagher PM, Skinner JS, Fowler FJ. Adverse effects of robotic-assisted laparoscopic versus open retropubic radical prostatectomy among a nationwide random sample of medicare-age men. JClin Oncol. 2012;30(5):513-518.

12. Gershman B, Psutka SP, McGovern FJ, et al. Patient-reported functional outcomes following open, laparoscopic, and robotic assisted radical prostatectomy performed by high-volume surgeons at high-volume hospitals. Eur Urol Focus. 2016;2(2):172-179.

13. D'Amico AV, Whittington R, Malkowicz SB, et al. Biochemical outcome after radical prostatectomy, external beam radiation therapy, or interstitial radiation therapy for clinically localized prostate cancer. JAMA. 1998;280(11):969-974.

14. Gore JL, Gollapudi K, Bergman J, Kwan L, Krupski TL, Litwin MS. Correlates of bother following treatment for clinically localized prostate cancer. J Urol. 2010;184(4):1309-1315.

15. Mulhall JP, Goldstein I, Bushmakin AG, Cappelleri JC, Hvidsten K. Validation of the erection hardness score. J Sex Med. 2007;4(6): 1626-1634.

16. Ko WJ, Truesdale MD, Hruby GW, Landman J, Badani KK. Impacting factors for recovery of erectile function within 1 year following robotic-assisted laparoscopic radical prostatectomy. J Sex Med. 2011;8(6):1805-1812.

17. Haglind E, Carlsson S, Stranne J, et al. Urinary incontinence and erectile dysfunction after robotic versus open radical prostatectomy: a prospective, controlled, nonrandomised trial. Eur Urol. 2015;68(2): 216-225. 
18. Dahl DM, Barry MJ, Mcgovern FJ, Chang Y, Walker-Corkery E, Mcdougal WS. A prospective study of symptom distress and return to baseline function after open versus laparoscopic radical prostatectomy. J Urol. 2009;182(3):956-966.

19. Herlemann A, Cowan JE, Carroll PR, Cooperberg MR. Communitybased outcomes of open versus robot-assisted radical prostatectomy. Eur Urol. 2018;73(2):215-223.

20. Trinh QD, Bjartell A, Freedland SJ, et al. A systematic review of the volume-outcome relationship for radical prostatectomy. Eur Urol. 2013;64(5):786-798.
21. Bianco FJ, Riedel ER, Begg CB, Kattan MW, Scardino PT. Variations among high volume surgeons in the rate of complications after radical prostatectomy: further evidence that technique matters. J Urol. 2005;173(6):2099-2103.

22. Mandel P, Preisser F, Graefen M, et al. High chance of late recovery of urinary and erectile function beyond 12 months after radical prostatectomy. Eur Urol. 2017;71(6):848-850.

23. Briganti A, Gallina A, Suardi N, et al. Predicting erectile function recovery after bilateral nerve sparing radical prostatectomy: a proposal of a novel preoperative risk stratification. J Sex Med. 2010;7(7):2521-2531.
Cancer Management and Research

\section{Publish your work in this journal}

Cancer Management and Research is an international, peer-reviewed open access journal focusing on cancer research and the optimal use of preventative and integrated treatment interventions to achieve improved outcomes, enhanced survival and quality of life for the cancer patient The manuscript management system is completely online and includes a very quick and fair peer-review system, which is all easy to use. Visit http://www.dovepress.com/testimonials.php to read real quotes from published authors. 